\title{
Google Scholar and the Library Web Site: The Early Response by ARL Libraries
}

\section{Laura Bowering Mullen and Karen A. Hartman}

\begin{abstract}
With the introduction of Google Scholar in November 2004, research libraries faced the decision of whether to integrate this "blended" resource into their collections and services via their library Web sites. The authors are members of a Web Advisory Committee and present a case study detailing Rutgers University Libraries' experience with integrating Google Scholar onto the library's Web site. A descriptive study of all ARL university members' library Web sites also was undertaken to determine how other academic libraries were treating Google Scholar in July 2005. Did ARL libraries place Google Scholar on alphabetical lists of indexes and databases, subject guides, or in OPACs, for instance? Results from this study are presented and implications of putting Google Scholar on the Web site are discussed for all major user groups.
\end{abstract}

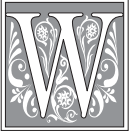

hen Google Scholar first appeared in November 2004, the library world was abuzz with questions, concerns, and tempered enthusiasm. At Rutgers University, librarians quickly began discussing it in meetings, including it in instruction sessions, trying it out with patrons at the reference desk in cases where a couple of scholarly full-text articles on a specific subject would suffice, using it to quickly verify incomplete interlibrary loan citations, and informally comparing its citation analysis capabilities to those of our other venerable subscribed-to resources. The librarians soon became aware that, in addition to being an easy way to search for a few scholarly articles, Google Scholar was another tool that could drive usage of their fee-based resources while promoting discovery of open-access materials. Discussions began with regard to adding it to library Web pages in some fashion to make patrons more aware of it. Google Scholar appeared to offer the library scholarly value at no cost.

University members of the Association of Research Libraries (ARL) and their Web committees have recently had to grapple with Google Scholar and make decisions regarding its integration into services and collections. Google Scholar is a different type of "blended" resource, one that allows a patron to search for all types of scholarly materials, many in fulltext format. It is especially valuable for the researcher who happens to be affiliated with a research institution and can link to

Laura Bowering Mullen is the Behavioral Sciences Librarian in the Library of Science and Medicine at Rutgers University Libraries; e-mail: lbmullen@rci.rutgers.edu. Karen A. Hartman is Social Sciences Librarian in the Archibald S. Alexander Library at Rutgers University Libraries; e-mail: khartman@rci. rutgers.edu. 
subscribed full-text either on-site at the library or through remote access. Scholarly materials found in Google Scholar may include peer-reviewed articles as well as full-text of dissertations, theses, preprints, and technical reports from all subject areas. According to the Google Scholar Web site, materials are included from scholarly publishers, universities, professional societies, and preprint repositories. The principal engineer for Google Scholar, Anurag Acharya, has focused development of the product on the concept of "versioning," or gathering all the differing versions of a single scholarly work together in one place. ${ }^{1}$ Librarians can see the value of displaying at once all possible versions of an author's work, including preprints, postprints, self-archived journal articles, conference presentations, and technical reports. In some ways, the introduction of Google Scholar has forced academic librarians to analyze the relationships among publishers, vendors, free search engines, and research-level libraries. The relationship between libraries and Google Scholar, unprecedented in that it does not depend on sales, has implications for the library Web site. It is an example of a new type of collaboration between a commercial enterprise and academia.

Google Scholar provides discovery as well as access, and librarians can promote its use through the Web site. Scholarly journal publishers are participating in initiatives such as CrossRef while making their content available to Google Scholar. ${ }^{2}$ Librarians are working with their link resolver products, and libraries are participating in initiatives such as OCLC WorldCat, which is making the book materials more discoverable. With the ability to set "Preferences" and personalize search in Google Scholar by moving a chosen institution's holdings to the top of the relevancy ranking, we are seeing the integration of institutionspecific identification to results.

Following Rutgers University Libraries' experience with integration of Google Scholar into collections and services, a study was undertaken to determine how other ARL libraries were handling this new type of important resource. The authors have studied the Web sites of ARL libraries to get a "snapshot" at this point in time of how academic libraries are integrating Google Scholar into their collections and services via their Web sites. In addition to the descriptive study of Google Scholar on ARL Web sites, the local experience at the Rutgers University Libraries is presented.

\section{Review of Relevant Literature}

With the introduction of Google Scholar, libraries have struggled to find ways to make decisions about how to integrate such a product into their collections via their Web sites. Few scholarly articles have been published to this point analyzing Google Scholar's role in academic libraries' collections or services or, specifically, how academic libraries are deciding to integrate it into their Web sites. As Google Scholar was introduced only recently, this literature will surely develop with time. In addition to the scholarly literature, development of the product and reaction to it by librarians may be studied through various articles, blogs, and news items as well as by visiting the Google Scholar Web site. ${ }^{3}$ As a free scholarly search engine that bridges to academic fee-based library content, Google Scholar was integrated into some library Web sites early on in its development. According to a review in The Charleston Advisor, Google Scholar "has gained widespread acceptance and is linked from the websites of highly respected libraries." ${ }^{4}$

\section{Early Google Scholar Literature}

Many of the articles and editorials appearing in the library literature detail the pros and cons of adding Google Scholar to the offerings of academic libraries. ${ }^{5}$ Advantages discussed informally in many forums include the ability to retrieve only scholarly material when searching, the usefulness of the "cited by" feature, Google Scholar's potential metasearch ca- 
pability, and the value of pushing usage of the library's fee-based electronic resources. Google Scholar, without charge, offers personalization through the "Preferences" search function, discovery of repository content, a one-stop shop for open-access publications, and a vehicle for discovery of the institutions' book collections. As all ARL libraries are OCLC WorldCat participants, patrons using Google Scholar at these libraries will find their institutions' book materials highlighted. Affiliates of ARL libraries will be able to link to their libraries' extensive holdings of subscribedto content from Google Scholar.

Conversely, Google Scholar raises many questions and concerns for academic librarians. With Google Scholar still a beta product with a "plug-and-play" development scheme, and almost all revenue generated by advertisements on the regular Google product, libraries are opening their Web pages to a new type of commercial enterprise. Librarians are not sure what their role is in the evolution of the product and are not an integral part of the development team. Concerns have been raised about the comprehensiveness of the indexing and the lack of a definition of "scholarly," as well as the issue of whether students should be encouraged to look beyond what is offered by Google. Early comments by Chuck Hamaker and Brad Spry discuss librarians' need to know what is being indexed by Google Scholar, what level of currency can be expected, and what the differences in access to content from various publishers will be. ${ }^{6}$ Even though many questions remain to be answered, some ARL libraries have moved to integrate Google Scholar into their Web sites.

It may be advantageous for academic library Web sites to include as many citation analysis sources as are currently available so that researchers can maximize results for any given author or article. Google Scholar is providing valuable citation data for many of the materials it indexes, especially those publications outside the traditional journal literature. The scholarly literature does contain some early attempts at comparison between Google Scholar and the Thompson/ISI citation analysis products. Richard K. Belew's recent study of 203 publications collectively cited by more than 4,000 other publications showed that Google Scholar's data citation counts "showed surprisingly good agreement" with the Thompson/ISI product. ${ }^{7}$ Belew adds the caveat that publications in books and conference proceedings are more likely to be included in Google Scholar whereas journal articles are better indexed by the Thomson/ISI product. ${ }^{8}$ Marcus A. Banks cautions that some librarians feel that Google Scholar's "cited by" algorithms are not fully reliable. ${ }^{9}$ Kathleen Bauer and Nisa Bakkalbasi, in a comparison of Google Scholar, Scopus, and Web of Science, suggest that no one citation analysis source may be considered comprehensive anymore for collecting the citation counts of a particular author or article. ${ }^{10}$

Banks also suggests comparison of Google Scholar with Elsevier's Scirus search engine. ${ }^{11}$ Dean Giustini and Eugene Barsky point out that one of the differences between these two free scholarly search engines is that Scirus clearly lists the sources that make up its content whereas Google Scholar does not. ${ }^{12}$ As for comparison with Scirus, Laura M. Felter advocates the integration of the free tools that benefit researchers, including Google Scholar and Scirus, with current offerings. These tools should be embraced and not seen as threatening. ${ }^{13}$ Greg R. Notess cautions that although both Google Scholar and Scirus have potential value for information professionals and end users, plenty of problems remain: "Other search tools continue to serve scholarly researchers more effectively." 14

\section{Library Web Site Literature}

To better understand how academic libraries might make decisions regarding integration of free Web-based indexes and databases, especially Google Scholar, onto their Web pages, a survey of the Web site management and design literature was 
undertaken. Although there is a paucity of literature that would give guidelines to librarians making decisions about the implications of adding free electronic databases to their Web sites directly alongside the purchased subscription products, it is possible to turn to the corpus of literature discussing integration of other types of free electronic resources into Web lists, research guides, instruction tools, and OPACs. Most of the available literature deals with the management and listing of free electronic resources such as Web sites, open-access journals, or electronic book collections on library Web lists. Peter Burnett and Christina Seuring discussed methods of prioritizing Internet materials, selection and access issues, the treatment of fee-based versus free electronic resources, and the integration of these resources into the OPACs of large university libraries. They concluded that "the inclusion of internet resources is in the interest of the support of research and education."15

Lesley M. Moyo presented a comprehensive look at the collaborative environment necessary when integrating free Web content into collections and discussed issues involved with access and public services for different types of electronic resources. Advantages of using Web lists for enhanced access are discussed. Moyo believes that when free Internet materials have been evaluated by librarians and deemed to have scholarly value, it would serve users better to integrate these materials alongside the subscription products for more seamless access. $^{16}$

\section{Usability of Library Web Sites}

Usability studies of academic libraries' Web sites are fairly common in the literature. It is important to take into account how users are approaching library Web sites when planning how to present resources. Barbara J. Cockrell and Elaine Anderson Jayne discussed the difficulties that all user groups experience when using library Web sites with their complicated lists of indexes and databases. Us- ability tests reveal that the way material is arranged, labeled, and presented on the Web site has a major impact on users. ${ }^{17}$ Efficiency of the use of the Web site comes from organizing information by type of material, giving users the shortest path clickwise to the materials they need. According to Elsevier's User-Centered Design Group, a Web site should be organized around certain user tasks. Elsevier's studies show that users' most frequent task is searching for journal articles, indexes, and books while conducting research. Chris Jasek has reported that 85 percent of people come to the library Web site to find research materials such as journal articles. ${ }^{18}$ Library Web sites incorporating Google Scholar will allow users, especially the affiliated users of ARL libraries, to search for and discover "scholarly" journal articles.

\section{Free Web Indexes and the OPAC}

To determine whether Google Scholar and other free Web-based indexing/search engine products should be integrated into the OPAC as well as included on Web lists, the cataloging literature was consulted for best practice guidelines. Much of the available literature on integration of electronic resources into OPACs focuses on subscription-based products. Less is available about whether the library should include free "blended" resources such as Google Scholar in the OPAC. Gail Herrera and Lynda Aldana discussed the approach taken for purchased electronic resources at the University of Mississippi Libraries whereby all electronic materials have been made available via the Web-based catalog. The catalog becomes "the base for all library resources regardless of format," and representing resources in the catalog enhances user awareness that the library is funding collections. ${ }^{19}$ Xiaotian Chen and colleagues have presented results of a survey and a discussion about cataloging, access versus ownership, and display of electronic resources in academic and research libraries. Their literature review shows that there is general consensus that 
the OPAC should be the primary means of access to electronic journals and electronic books. The disadvantage for the library patron of having to search in multiple places is noted as is the fact that policies for cataloging of electronic resources are often made at the local institutional level. Even when discussing subscription-based electronic resources, libraries use many different ways of providing access. In determining where electronic resources should be placed, "there existed no common agreement among libraries concerning which categories of resources should be listed in the catalog, which in the Web list and which in both." 20

\section{Open-Access Materials and the Library Web Site}

Lastly, the literature of the open-access movement was consulted to determine whether and where academic libraries are placing resources that index such publications on their Web sites. Google Scholar is an important vehicle for the discovery of open-access literature. Malcolm Getz speaks to the ability of Google Scholar to make essays published in open journals more conveniently accessible. Also, the "cited by' counts found through Google Scholar will be used as a measure of value when judging the impact of publications in open-access journals. ${ }^{21}$ Recent articles have demonstrated that there is greater research impact when articles are made freely available online..$^{22}$ Placing Google Scholar on library Web sites can be said to further drive impact by enhancing the discovery of open-access materials from the library Web site.

The literature studied gave no conclusive guidelines that ARL libraries might turn to when faced with the decision to add a resource such as Google Scholar to the library Web site, either as part of a Web list that may have heretofore been reserved for subscribed-to indexes and databases or to OPACs. This type of important decision is often left to Web committees or Webmasters. More research is needed in the area of decision making about integrating free
Web products into research library Web sites in order to make sure these portals to the library's collections and services remain effective and consistent for a multiplicity of user groups.

\section{Case Study: Integration of Google Scholar into the Rutgers University Libraries' Web Site}

As members of the Web Advisory Committee (WAC) of the Rutgers University Libraries, the authors were part of the process that surrounded the decision to add Google Scholar to our library's offerings via the Web site.

In February 2005, following a period of time when librarians informally tested use of Google Scholar in the libraries, a move was made to suggest a more formal integration of the product into the library's suite of offerings. One of the science librarians approached the Associate University Librarian for Communications and Public Services with the suggestion that Google Scholar be placed on our Web pages. The AUL gave a charge to WAC to make recommendations to the Public Services Council about the integration of Google Scholar into appropriate places on our library Web site. A committee under the aegis of the Public Services Council, WAC's charge may be found on the Rutgers University Libraries' Web site. Members of WAC work with the Webmaster to "advise the webmaster on making new electronic resources available and solicit and provide content for creation and expansion of needed web pages." 23

Usually, the protocol followed when adding a new scholarly resource would come from the procedures listed by the Public Services Council. The step-by-step guidelines for adding resources in various categories are listed on our Web site. Listed under the heading "Making Additions to our Web Pages," the procedures primarily include categories that refer to licensed databases or electronic journals, trials for electronic products, or even nonlicensed products. ${ }^{24}$ WAC members did not find any specific guidelines that 
would help in determining how best to integrate this new free "blended" Webbased resource into our Web pages and Web lists, especially whether to place Google Scholar on the alphabetical list of indexes and databases. The alphabetical and subject lists of indexes and databases on the Rutgers University Libraries Web site are composed almost entirely of feebased subscription products.

As background to its discussions, WAC turned to the Web sites of other ARL libraries and began to look at how these academic libraries were handling Google Scholar. It was seen at that early date that some academic libraries had already incorporated Google Scholar into their Web pages. As the Web sites including Google Scholar were analyzed, there appeared to be no real consistency in the treatment of the resource by research libraries.

WAC members discussed how best to represent Google Scholar on the Rutgers University Libraries Web page. At first, WAC decided on an approach that would not treat Google Scholar exclusively but, instead, place it in context among other free "scholarly" search engines, indexes, and databases. It was left to the WAC members to come up with a list of resources that were in a similar task grouping to Google Scholar. After much discussion, a separate page was mocked up that was to place Google Scholar among other openaccess resources. WAC would simply title this page "Open-Access Resources." The short list of resources decided on included DOAJ (Directory of Open Access Journals), Scirus, OAIster, and Google Scholar.

After further discussion, WAC realized that Google Scholar was offering something more than the other open-access resources listed, namely, enhanced search capabilities, the addition of cited references, and, most important, the ability of libraries to link the searcher to the institution's subscribed-to resources through the local link resolver. ${ }^{25}$ WAC then decided to change course and create a situation where Google Scholar would stand alone among comparable resources.
The fact that it was in beta, had not been completely forthcoming about many aspects of its development, and was a free resource did not seem to diminish its potential usefulness to library patrons as both a search tool and a mechanism to raise awareness of the libraries' subscribed-to resources.

Therefore, WAC decided to place Google Scholar on the Libraries' venerable alphabetical list of indexes and databases. Moreover, Google Scholar would become an item in the Libraries' news and be placed on lists of general science resources. It already had been incorporated into various subject-based research guides, especially in the sciences fields. The authors created a description page about Google Scholar because Rutgers University Libraries maintains such a page for every index and database that resides on the alphabetical list. This description page includes information about the content of the resource and also lists any access information available for on-site as well as for remote access by Rutgers affiliates. ${ }^{26}$

The content of the description page and recommendations for Google Scholar's placement on certain places on the Web site went to the Public Services Council for approval. The Public Services Council, under the aegis of our AUL for Public Services and Communications, approved the page and the recommendation to add the resource to the Web site in the locations suggested. The charge to proxy the resource and to add it to our link resolver went to our systems department, and after completion of the technical aspects of the project, the resource was added to the libraries' alphabetical list of databases, front page news, and general sciences database lists. Selectors would have responsibility for incorporating the resource into subject guides as they wished. Google Scholar was added to every science "quick guide," a series of pathfinders produced and distributed online and in paper by the science librarians.

Following this local process of integrating a free scholarly index/database 
alongside Rutgers' myriad fee-based offerings, the authors became interested in more formally researching how other ARL libraries had decided to treat Google Scholar, whether these academic libraries had decided to include Google Scholar in their offerings or had chosen a different course. Had some libraries decided that it was inappropriate to place a free index that was being developed commercially and still in beta on the library Web site? Since more than half a year had elapsed from the introduction of Google Scholar to the library community, a research study was conducted using information found on the Web sites of ARL libraries. How widely had Google Scholar been accepted by other academic research libraries by the summer of 2005 ?

\section{Method}

The 113 ARL university members comprised the sample studied. ${ }^{27}$ The library homepages of these institutions were examined for paths or links to Google Scholar. As a check, links to Scirus, a similar science-oriented free resource, also were investigated. An a priori coding scheme was developed of places where the authors expected to find links to Google Scholar or information about it (e.g., database lists, subject research guides, the OPAC, class/instruction guides, library news and/or blogs, Web pages of science or engineering libraries, and so on). Five university libraries were chosen at random from the ARL Web site and the two authors together tried to apply the coding scheme to them. This allowed refinement of the coding instructions so that they more accurately and comprehensively covered the actual examples that would become apparent in the course of the study. As a check of the reliability of the revised coding scheme, the authors chose another ten libraries at random and independently attempted to apply the coding instructions to them. The authors agreed on 94 percent of all data coded from these ten libraries. The few disagreements were discussed and reconciled, which resulted in one additional minor adjustment to the coding instructions. There was then sufficient confidence in the coding procedures for one of the authors to be able to code all the remaining data.

Data were collected during the week of July 10, 2005. Starting from the 113 ARL university library homepages, the final coding scheme necessitated answering fourteen separate questions for each library:

- Does Google Scholar appear anywhere on the library homepage (outside news, which is coded separately below)?

- Is Google Scholar represented in the online public access catalog (OPAC)?

- Does Google Scholar appear on the alphabetical list of indexes/databases? (This question also was asked about Scirus.)

- Does Google Scholar appear on any database list organized by subject (e.g., biology databases, history databases). (This question also was asked about Scirus.)

- Is Google Scholar listed on any subject research guides? (This question also was asked about Scirus.)

- Is Google Scholar listed on a Web page of search engines/Internet search tools? (This question also was asked about Scirus.)

These first six questions refer to paths to resources that have typically been vetted in a more formal or regularized manner and therefore may be considered to be more enduring. The following two questions refer to links that are likely to be more time or date sensitive and, as a consequence, more ephemeral.

- Is Google Scholar listed or presented in any form of instruction such as class guides or workshop information? (These typically disappear at the end of the current semester. This question also was asked about Scirus.)

- Does Google Scholar appear in library news and/or library blogs? News items can change on a daily, weekly, monthly basis. 
In addition, because assumptions could not be made about the underlying organizational models at ARL libraries with respect to oversight of branch library Web pages, the following question was asked:

- Does Google Scholar appear anywhere on the Web pages of the library's branches? (Note that this was a simple yes/no question; it does not count appearances on Web pages of multiple branch libraries.)

Finally, it was noted whether each of the 113 university libraries had granted Google Scholar institutional access to its holdings. This last piece of information was obtained by searching for each institution by name on the "Scholar Preferences" page.

This study is largely exploratory, as its major research focus is simply on how widely Google Scholar has been accepted and incorporated by academic research libraries at one particular point in time relatively early in its history, about eight months after its introduction in the summer of 2005. Nonetheless, two hypotheses guided some of the analyses. In particular, it was expected that more paths to and information about Google Scholar would be found at those universities that already had granted Google access to their holdings. In addition, it was hypothesized that those libraries that had included Scirus as a research tool on their Web sites would be more likely to provide links to another free scholarly search engine such as Google Scholar.

\section{Results}

How widely had Google Scholar been accepted by 113 university members of ARL in the summer of 2005? Several different methods of measuring acceptance are represented in the data:

- Only six libraries (5\%) placed a link to Google Scholar directly on the library homepage and only two of these included the Google Scholar search box.

- Six libraries (5\%) cataloged Google Scholar in the OPAC.

- Only 27 of the 113 ARL institutions (24\%) included Google Scholar on their alphabetical list of indexes and databases.

- Sixteen (14\%) included Google Scholar in lists of databases organized by subject.

- Google Scholar appeared on subject guides at only 14 institutions (12.5\%).

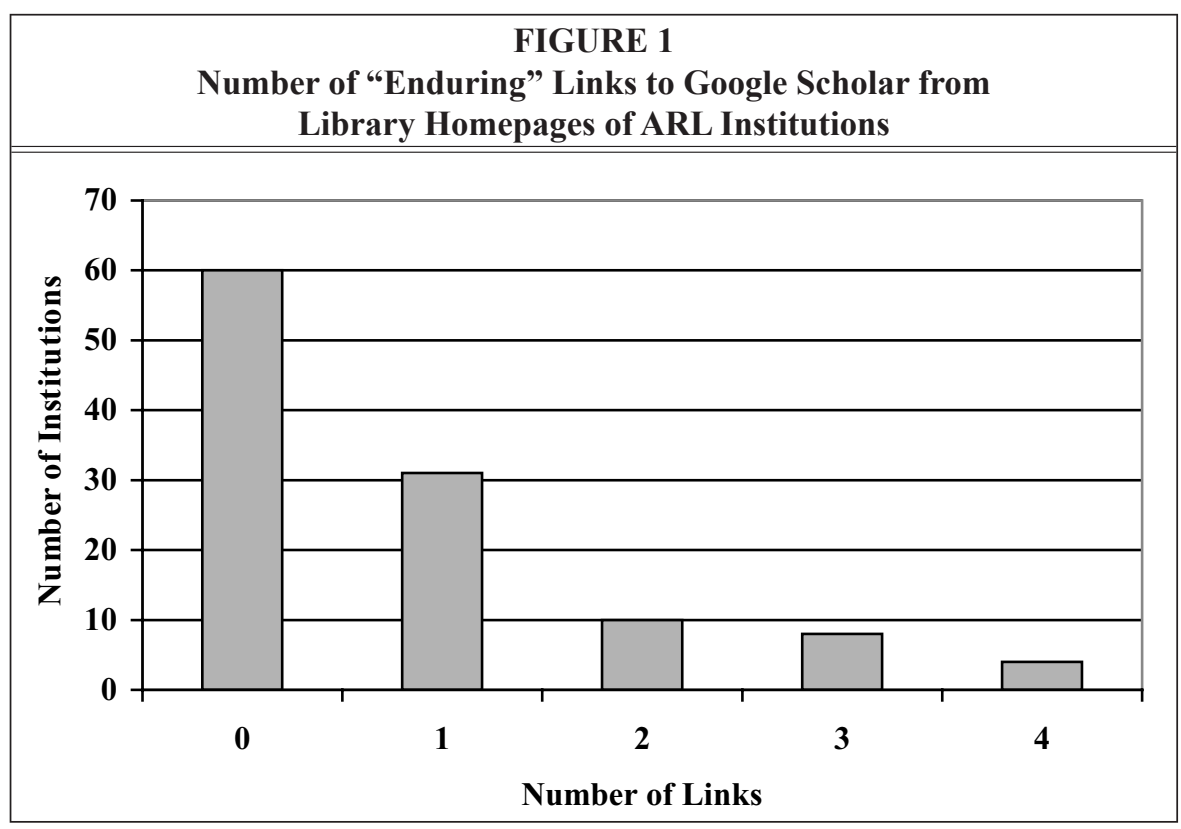




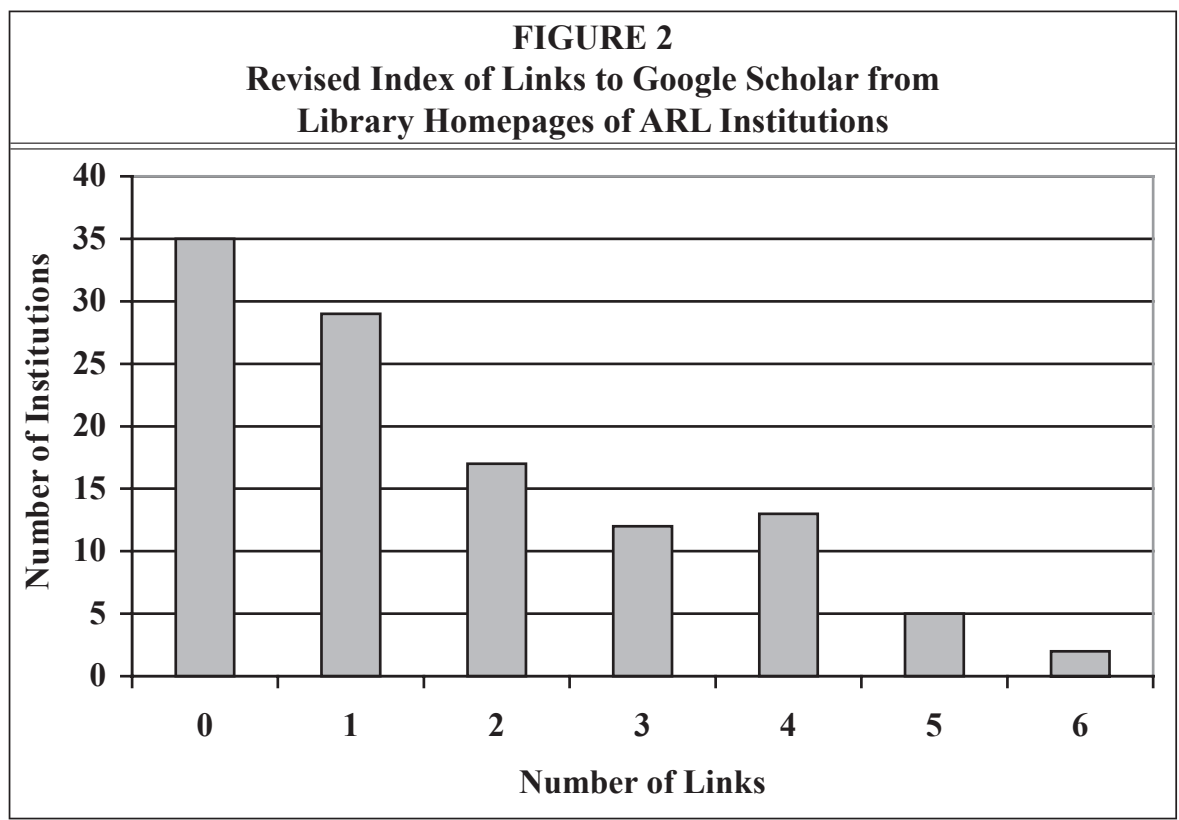

- Google Scholar was listed as a search engine or Internet search tool at 22 institutions (19.5\%).

- Google Scholar appeared on instructional guides or workshop information at 23 institutions (20\%).

- Items about Google Scholar appeared in the library news or blogs of 31 $(27 \%)$ of the libraries.

- Interestingly, Google Scholar did appear somewhere on the Web pages of branch libraries at 43 of the 113 ARL institutions (38\%).

An index was created that simply counted the first six, more permanent paths to Google Scholar listed above. A rationale for focusing on these six was the expectation that if the Web pages of these libraries were surveyed again a year from now, these same links would exist. In theory, the index could range from 0 to 6 , but in practice the highest score obtained was 4 , with a mean of .81. Sixty ARL libraries did not have any of these paths $(53 \%)$, and $31(27 \%)$ had only one. That is, 80 percent of the ARL libraries had none or only one path, as measured. These data are illustrated in figure 1.
At the time of the data collection, 43 of the 113 libraries had granted institutional access to Google Scholar. The authors hypothesized that these 43 partners would provide more links or paths to Google Scholar than nonpartnering institutions. However, the results did not bear this out. The 43 partnering institutions provided an average of .86 paths $(\mathrm{SD}=1.06)$ to Google Scholar compared to .77 paths $(\mathrm{SD}=1.12)$ provided by nonpartnering institutions $(t(111)=.42, p<.68)$, a clearly nonsignificant difference.

The index was recomputed with the addition of three paths that represent more ephemeral or less central routes to Google Scholar: its coverage in news; instruction that included Google Scholar; and the appearance of Google Scholar on the Web pages of branch libraries. The reconstituted index's overall average more than doubles to 1.66. Clearly these three links were utilized relatively more than the six permanent links. Moreover, it is apparent that the jump in the overall mean of the revised summary index is due disproportionately to the 43 partnering institutions. The partnering institutions provided an average of 2.07 links (SD = 
1.71) compared to 1.41 links (SD = 1.54) for nonpartnering institutions. This is now a significant difference: $t(111)=2.11, p<.04$. These data are illustrated in figure $2 .^{28}$

The authors also expected to find an association between those libraries that included Scirus as a research tool and those that provided links to Google Scholar. The appearance of Scirus on the alphabetical list of databases, lists of databases organized by subject, on subject guides, on instruction, class or workshop guides, and on search engine guides/Web pages was noted. As shown in figure 3, by these five criteria, Scirus is even less visible than Google Scholar on library Web sites. As hypothesized, however, in every case there was a statistically significant relationship between those institutions that provide links to Google Scholar and those that provide links to Scirus. (tau $\mathrm{b}$ ranges from .23 to .40 ).

\section{Discussion}

Given the amount of discussion about
Google Scholar in forums devoted to developments in the academic library world, it is somewhat surprising that many libraries have largely not incorporated this resource into their Web sites. Indeed, even allowing Google institutional access to holdings as a partner did not translate to greater integration of Google Scholar in the library Webs sites at this point in time. Partners were more likely to provide coverage of Google Scholar in news or blogs and include it in class guides or special training workshops, but they were no more likely than nonpartners to place it in more permanent locations such as the OPAC or subject guides. Google Scholar did appear on the Web pages of branch libraries, most often on those with a science focus, a not surprising result given the product's current emphasis on science and technology. This situation will undoubtedly evolve with time and with the development of Google Scholar. As a caveat, it should be noted that the authors did not seek information about

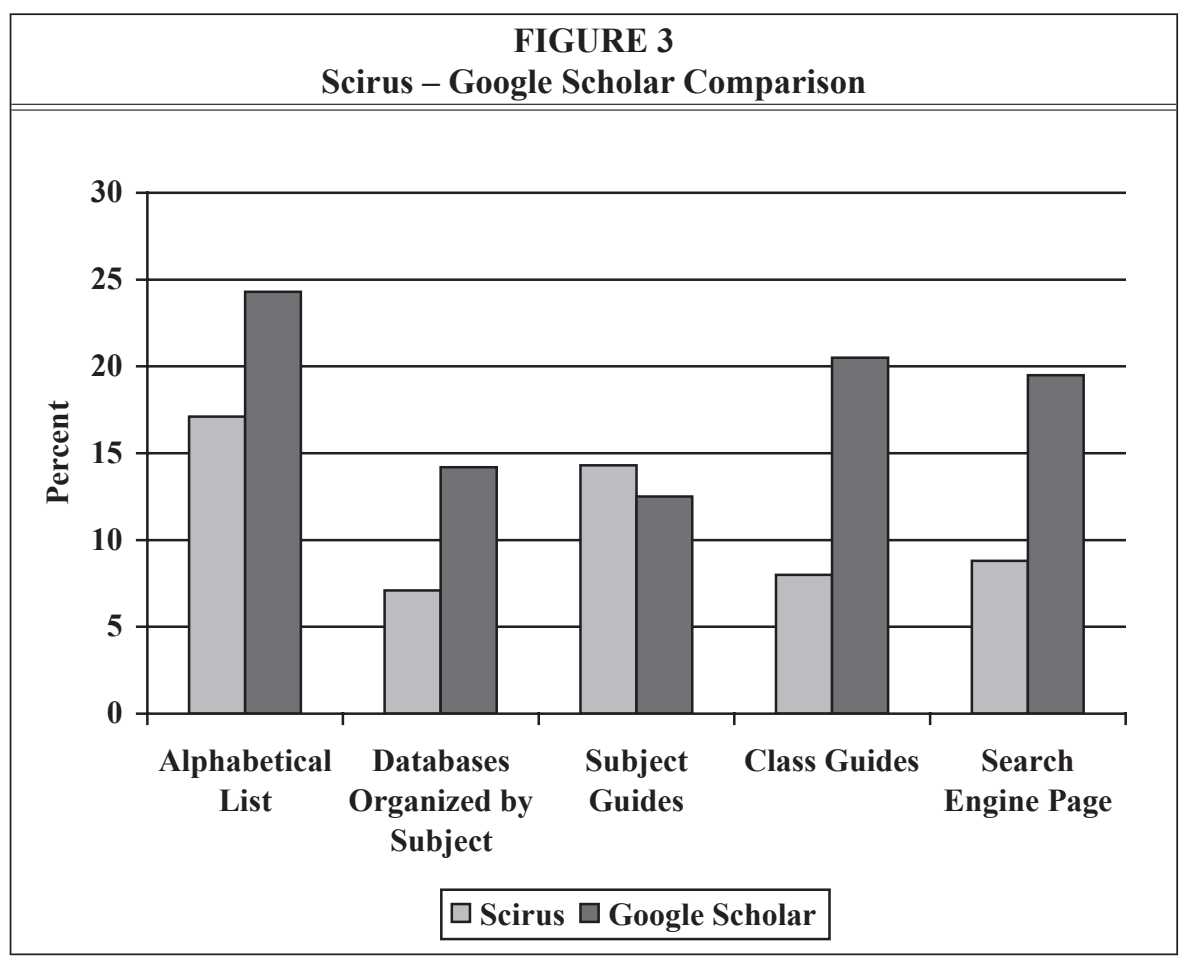


the decision-making process of individual ARL libraries and it is only speculation at this point as to reasons why an institution would decide to include Google Scholar or not. ${ }^{29}$ Future research is needed to determine how librarians and Webmasters make decisions about adding resources to their alphabetical lists of indexes and databases, subject guides, and OPACs.

\section{Integration of Google Scholar into ARL Web Sites: Implications for Different User Groups}

What does it mean when an academic library presents a resource on its Web site? Are librarians recommending that resource, bestowing an imprimatur on it or otherwise letting their users know that the library considers it valuable? Jasek suggests that it may be beneficial to put links to frequently used databases directly on the homepage, offering the shortest path to users. ${ }^{30}$ Some librarians have felt that prominent placement on the Web site is justified for indexes and databases that represent a large budgetary outlay for the library; others feel that a link to subscription databases should be prominently displayed on the library homepage for reasons other than for money spent. ${ }^{31}$ There have been good reasons for keeping free Web-based indexes and databases off lists made up of subscription products. One reason that free Web content has been kept separate is due to a lack of quality control. $^{32}$

\section{Implications for Students}

How will a decision to include Google Scholar in prominent places on the library Web site affect the information-seeking behavior or the perceptions of users when starting the research process? Usability tests have shown that users do not understand library terms and may have difficulty with concepts. Despite effective library instruction and online and print guides to using the library, many students still have no idea how or where to begin their search. ${ }^{33}$ We do know that users recognize Google and that they will often bypass the library when starting a search. Deborah Fallows mentions that there are types of information, such as journal articles, that searchers may not expect to find online, but Google's "new scholar search" might change minds. ${ }^{34}$

Users expect to be able to enter simple search terms into a single interface and retrieve the full range of materials available. ${ }^{35}$ Vendors are aware that "librarians want Boolean search capabilities and students want the ease of using Google." ${ }^{\prime 36}$ Our sites can be known as the comprehensive and appropriate place for students to look for research materials. Users are not physically coming to the library and have come to depend on successful Web pages to get started. ${ }^{37}$ At least if they start with Google Scholar from our Web sites rather than from the open Web, they will likely notice our vetted subject-oriented indexes and databases and be more tempted to browse.

Other studies have indicated that students often try to find scholarly articles in the OPAC. ${ }^{38}$ How many ARL libraries that have represented Google Scholar on their Web pages have actually catalogued it to the OPAC? This study finds that only six ARL institutions have included Google Scholar in their OPACs whereas 27 have included it on their alphabetical list of indexes and databases. Clearly, ARL libraries that have included Google Scholar on Web lists have not rushed to catalog it in the OPAC. There appears little consistency in how resources are added to OPACs, another place where students may be starting their research.

The library's extensive lists of resources presented on a Web site can be overwhelming. Often hundreds of indexes and databases are presented in alphabetical and subject lists. Besides longer and longer lists of indexes and databases and confusion on the best ways to instruct students to choose which databases to start with, publishers and vendors sometimes name their products with titles such as ASFA 1 , Compendex, or SCOPUS. It is not surprising that students would not be 
able to link these types of names with the subject content they contain. How is a user to choose from a list of databases when starting a subject search? Google Scholar, on the other hand, is aptly named to attract students and researchers to the more scholarly aspects of the familiar Google search engine. Less contact with reference librarians as shown by declining reference desk statistics means more users will start with the Web site and will have the difficult task of choosing an appropriate subject resource based on its title. Will the placement of any Google product on our Web pages alongside our subscribed-to resources offer a familiar name that students will gravitate toward when they are not sure what else to choose? This study shows that only 27 of the 113 ARL libraries have decided to place Google Scholar on their alphabetical list of indexes and databases. It is possible that some librarians would rather that students and researchers use only the more traditional subscribed-to indexes and databases when searching for scholarly literature. It also may be that the alphabetical list of indexes and databases at some research libraries has been reserved for subscribedto resources.

Do teaching faculty expect librarians to present a different kind of material to students than what is produced by Google, even if they tell us it is "scholarly?" Librarians may need to educate faculty and students about this Google product and justify its inclusion in their Web sites. With faculty trying to steer undergraduates away from Google and onto the libraries' Web sites and into library buildings, will seeing Google Scholar on the Web site alongside accepted subject databases be met with incredulity? Will students stick with the recognizable old favorite to the dismay of their instructors? In some cases, faculty members have defined "scholarly" to their students as articles that are peer-reviewed, a refinement in search that Google Scholar currently does not allow. Librarians will still need to assist users in finding the most appropriate source. By including Google Scholar on Web sites alongside subscribed-to resources, librarians may be seen as promoting its use for subject searching of scholarly material as well as suggesting that it is "on par" with the other vetted indexes and databases listed.

\section{Implications for Scholars/Researchers}

As for another of libraries' user groups, the researchers, Harnad states that the optimal situation is "online availability of the entire refereed research corpus; availability on every researcher's desktop, everywhere, 24 hours a day; interlinking of all papers and citations; and fully searchable, navigable, retrievable, impact-rankable research papers." ${ }^{\prime 39}$ Google Scholar appears to be a tool that has all these capabilities.

Our faculty and students are potential authors of scholarly journal articles and will want to see their publications, in all possible versions, become as widely available to researchers as possible. Highlighting Google Scholar on our Web sites will push access to our own authors' publications as well as increase the research impact of these materials. A consideration for publishers that do not participate with Google Scholar might be that authors will go elsewhere to publish their research results because there is the danger that their articles will not be discovered by as many searchers. Authors will want to be aware of any product such as Google Scholar that can heighten the research impact of their work. In time, impact also may be measured in terms of the number of downloads a particular article gets, and authors will want to maximize Web visibility of all versions of their publications.

Another feature of Google Scholar that has pushed it to the forefront is the inclusion of "cited references." If this feature is expanded, and if studies show it to be a comprehensive means of citation analysis, there may be great implications for the ISI/Thompson products as well as others such as SCOPUS and some of the subject-specific indexes that have recently incorporated cited references. If Google 
Scholar is complementary to other citation analysis sources, listing it on our Web sites will benefit researchers by allowing for a more comprehensive listing of cited references for a given article.

\section{Implications for Librarians}

When deciding where a resource such as Google Scholar is best placed on the Web site, whether on database lists, in subject research guides, or in news for faculty and students, librarians must decide what type of resource it is. Google Scholar defies description in this sense. Is it an index/ database or commercial search engine? Will its placement affect other resources in unknown ways? In the paper world, it was easier to categorize resources, and we were talking about ownership, not access. Some have argued that librarians should not make a distinction between "free" and "paid for" when making materials available to users. ${ }^{40}$ For example, it is possible to adapt and expand Katz's criteria for the evaluation of print reference sources for use with the free electronic indexes. ${ }^{41}$ There must be criteria on which librarians responsible for Web site content make decisions regarding whether to include new types of free Web-based resources on the site and where.

There are many ways that the development of Google Scholar might affect libraries' subscribed-to abstracting and indexing services. These fee-based subject index providers will become more cognizant of customer service and development of value-added features as Google Scholar becomes an easy and convenient product with which to reach scholarly material at no cost. As for increasing downloads of subscribed-to journal content, usage statistics may help libraries see the effect that placing Google Scholar on our Web pages is having on usage of our collections. Acharya admits that libraries could set up systems to track usage of Google Scholar for reaching collections. ${ }^{42}$

Librarians may have philosophical, ideological, or ethical reasons for not including Google Scholar on their library's
Web site. As most of Google's revenue comes from advertisements, librarians may expect Google Scholar to include them in the foreseeable future. Google says that "ads are possible down the line." ${ }^{43}$ Google Scholar's Acharya also states that "we're focusing on trying to get the functionality to be what we want it to be before focusing on monetization." ${ }^{\prime 4}$ Will librarians feel differently about displaying Google Scholar from the Web site if advertisements became part of the package?

This study reveals that only two ARL libraries have chosen to place the Google Scholar free search box directly on their library homepages. For those libraries using the Google Scholar free search box, have the "terms of use" proved to be in line with the principles of the library Web site? According to section 1.5 of Google Scholar's terms, by using the Google Scholar search box, the user is agreeing, in part, that Google will be the "exclusive provider of Internet search services on the Site." 45 Is it possible that the library having to agree to these terms from Google explains, in part, why only two libraries have put the Google Scholar free search box on their front pages?

A related issue for librarians surrounds the use of library Web sites as a marketing vehicle for publishers. Google Scholar on our Web sites will push referrals to Google's journal publisher partners. For instance, according to Elsevier's de Heer, library Web sites are becoming one of the leading sources of referrals to Elsevier's Science Direct, an abstracting and indexing tool subscribed to by many ARL libraries. Looking at referrals to Science Direct from all sources, it is seen that 24 percent come from library Web sites. ${ }^{46}$ In this case, it may turn out that library Web sites are helping to market the publishers' product. For ARL libraries with their rich corpus of subscribed-to material, the relationship can be a mutually beneficial one. Publishers sell more products and libraries will see a concomitant rise in usage statistics of subscribed-to products, making it 
easier to justify spending money on these resources. For other types of libraries that do not subscribe to much of the content that Google Scholar bridges to, library Web sites could be a marketing vehicle for Google's publisher partners without any real benefit to the libraries' mission. This may be one reason why 96 percent of the large, urban libraries making up the Urban Libraries Council have not included Google Scholar on their websites. ${ }^{47}$

Google Scholar has been discussed as an alternative to federated search products because of its one-stop-shop approach to searching what it defines as scholarly materials. As library Web sites are the portals to an institution's scholarly resources, librarians have discussed Google Scholar's potential for metasearch across a wide array of publication types, including those from their own repositories. ${ }^{48}$ Other initiatives, for example ARL's Scholar's Portal Project and the Ontario Scholars Portal, have attempted to help link the user to vetted scholarly Internet materials. ${ }^{49}$ Google Scholar may someday function in a similar way for the wide variety of scholarly materials it contains, even though, unlike with the other portals, its development does not necessarily involve academic librarians directly.

Librarians should have a vested interest in the expansion of the open-access movement. Search engines such as Google Scholar are indispensable in making this material available to researchers. Should library Web sites include links to other open-access search tools such as Elsevier's Scirus? ${ }^{50}$ This study shows that Scirus is less represented on library Web sites in comparison with Google Scholar. Especially for those users not affiliated with a library rich in subscribed-to content, Google Scholar can aid in the discovery of alternate peer-reviewed open-access materials. With the name Google becoming so ubiquitous, publishers of open-access materials will find association with Google Scholar to be their best shot at maximum visibility whereas other indexes, such as OAIster, can crawl the deep Web but are still relatively unknown. ${ }^{51}$ Also, the open-access literature is more developed in the sciences and, indeed, scientific open-access publishers have responded with early press releases. For instance, BioMed Central's headlines in November 2004 read: "Google Scholar Good News for Open Access." 52 Google Scholar can be an important portal to the corpus of open-access material, especially in the sciences.

\section{Conclusion}

The results of this descriptive study are an attempt to illustrate the way that Google Scholar has been represented on ARL libraries' Web sites eight months after its release. Some libraries are placing Google Scholar alongside vetted scholarly indexes and databases with which we have a long history. Google representatives are sharing the stage at our conferences with many of the most prominent librarians of our time. On the other hand, some ARL libraries appear to be making informed decisions not to share the venerable library database lists with Google Scholar. Many ARL libraries do not include Google Scholar on their Web sites at all.

Librarians are heavy users of Google themselves and may be more apt to add the resource because they "trust" a familiar Google product. ARL head Duane Webster said of Google Scholar that "the arrival of this new service was welcome but noted the need for open dialog as it develops." ${ }^{53}$ Publishers, vendors, and the abstracting and indexing services are cautiously proceeding into the new realm of Google Scholar even as librarians wonder whether its capabilities will eclipse some of the traditional players in the academic library world. Carol Tenopir says of Google Scholar, "it does not replace the library collection. It expands access. The impact on abstracting and indexing services remains to be seen." ${ }^{54}$

Academic libraries need to continue to develop guidelines for decision making about Web site issues. While dealing with new types of resources in effective ways on their Web sites, libraries must always 
keep the user at the forefront. Librarians also must keep up with transformative or "disruptive" technologies that are on the horizon. ${ }^{55}$ Moreover, librarians responsible for content on Web sites have to be able to react quickly to technological change and, by doing so, remain relevant to the many user groups they serve. The introduction of Google Scholar presents a challenge as well as an opportunity for academic libraries. In a changing information landscape, Stephen Abram reminds librarians that one of the key things we can do is to "get on the bandwagon early" and evolve. ${ }^{56}$

\section{Notes}

1. Barbara Quint, "Library Collections Linked on Google Scholar for Free," Information Today (May 16, 2005). Available online at http://www.infotoday.com/newsbreaks/nb050516-1.shtml. [Accessed 26 May 2005].

2. The CrossRef Web site is available online at http://www.crossref.org. [Accessed 15 October 2005]. From the site: "CrossRef is an independent membership association, founded and directed by publishers and is the official DOI registration agency for scholarly and professional publications. CrossRef operates a citation-linking network that covers millions of articles." Information from Google for scholarly publishers can be found at http://scholar.google.com/scholar/publishers. html. [Accessed 20 October 2005].

3. The Google Scholar Web site is available online at http://www.scholar.google.com. [Accessed 15 October 2005]. Because Google Scholar is a new product and has caused a great deal of informal discussion in many library circles, it has been possible to follow both development of the product and reaction to it by librarians and other interested users through various library blogs. The following blogs have been accessed and read from November 2004 to October 2005: Making Links at http://makinglinks.uwindsor.ca:8087/mitas/sfxblog/; Digital Librarian at http:// digitallibrarian.org/; UBC Google Scholar Blog at http://weblogs.elearning.ubc.ca/googlescholar/; Lorcan Dempsey's Weblog at http://orweblog.oclc.org/archives/000615.html; LibraryCog at http://webvoy.uwindsor.ca:8087/artblog/librarycog/1100880268; ResourceShelf at http://www. resourceshelf.com/; On Google Scholar at http://schoogle.blogspot.com/; The Distant Librarian at http://distlib.blogs.com/distlib/; Library Web Chic at http://librarywebchic.net/wordpress/; Google Blog at http://googleblog.blogspot.com/.

4. Martin Myhill, "The Advisor Reviews...Google Scholar," Charleston Advisor 6, no.4 (Apr. 2005). Available online at http://www.charlestonco.com/review.cfm?id=225. [Accessed 29 June 2005].

5. Examples of articles discussing the advantages and disadvantages to libraries of Google and Google Scholar are: Brian Kenney, "Googleizers vs. Resistors," Library Journal (Dec. 2004): 44-46; Peter Jasco, "Google Scholar: The Pros and the Cons," Online Information Review 29, no.2 (2005): 208-14.

6. Chuck Hamaker and Brad Spry, "Google Scholar," Serials 18, no.1 (Mar. 2005): 70-72. Available online at http://serials.uksg.org/(k1cfb255t1223u45mpyq4hyy)/app/home/main. asp?referrer=default. [Accessed 18 October 2005].

7. Richard K. Belew, "Scientific Impact Quantity and Quality: Analysis of Two Sources of Bibliographic Data," arXiv\#: CoRR/0504036, 1 (Apr.11, 2005): 1-12.

Available online at http://arxiv.org/PS_cache/cs/pdf/0504/0504036.pdf. [Accessed 11 April 2005].

8. Ibid., 10.

9. Marcus A. Banks, "The Excitement of Google Scholar, the Worry of Google Print," Biomedical Digital Libraries 2, no. 2 (Mar. 22, 2005). Available online at http://www.bio-diglib.com/content/2/1/2. [Accessed 17 June 2005].

10. Kathleen Bauer and Nisa Bakkalbasi, "An Examination of Citation Counts in a New Scholarly Communication Environment," D-Lib Magazine 11, no.9 (Sept., 2005): 1-10. Available at http://www.dlib.org/dlib/september05/bauer/09bauer.html. [Accessed 11 October 2005].

11. Banks, "The Excitement of Google Scholar, the Worry of Google Print."

12. Dean Giustini and Eugene Barsky, "A Look at Google Scholar, PubMed, and Scirus: Comparisons and Recommendations," JCHLA/JABSC 26(2005): 85-89.

13. Laura M. Felter, "Google Scholar, Scirus, and the Scholarly Search Revolution," Searcher 13, no. 2 (2005): 43-48. Available online at http://www.scirus.com/press/pdf/searcher_reprint.pdf. [Accessed 18 October 2005].

14. Greg R. Notess, "Scholarly Web Searching: Google Scholar and Scirus," ONLINE 29, no.4 
(July/Aug. 2005): 39-41. Available online at http://www.infotoday.com/online/jul05/OnTheNet. shtml. [Accessed 15 October 2005].

15. Peter Burnett and Christina Seuring, "Organising Access to Free Internet Resources: An Overview of Selection and Management Issues in Large Academic and National Libraries with a View to Defining a Policy at Oxford University," Program: Electronic Library \& Information Systems 35, no. 1 (Jan. 2001): 15-31.

16. Lesley M. Moyo, "Collections on the Web: Some Access and Navigation Issues," Library Collections, Acquisitions, \& Technical Services 26 (2002): 47-59.

17. Barbara J. Cockrell and Elaine Anderson Jayne, "How Do I Find an Article? Insights from a Web Usability Study," Journal of Academic Librarianship 28, no.3 (May 2002): 122-32. Cockrell and Jayne cite Louis B. Rosenfeld and Peter Morville, Information Architecture for the World Wide Web (Sebastopol, Calif.: O’Reilly, 1998).

18. Chris Jasek, "How to Design Library Web Sites to Maximize Usability," Library Connect (2004): 1-15. Available online at http://www.elsevier.com/framework_products/promis_misc/ 672915lcpamphlets.pdf. [Accessed 18 October 2005].

19. Gail Herrera and Lynda Aldana, "Integrating Electronic Resources into the Library Catalog: A Collaborative Approach," portal: Libraries and the Academy 1, no.3 (2001): 241-56.

20. Xiaotian Chen, Larry Colgon, Courtney Greene, Elizabeth Lowe, and Conrad Winke, “EResource Cataloging Practices: A Survey of Academic Libraries and Consortia," Serials Librarian 47, no.1/2 (2004): 153-79.

21. Malcolm Getz, "Three Frontiers in Open Access Scholarship," Frontiers in Open Access Scholarship Workshop from Cornell University Open Access Repository (Jan.13, 2005). Available online at http://dspace.library.cornell.edu/handle/1813/307. [Accessed 18 September 2005].

22. Kristin Antelman, "Do Open Access Articles Have a Greater Research Impact?" College and Research Libraries 65, no.5 (Sept. 2004): 372-82; Steve Lawrence, "Free Online Availability Substantially Increases a Paper's Impact," Nature Web Debates (2001). Available at http://www. nature.com/nature/debates/e-access/Articles/lawrence.html. [Accessed 17 August 2005].

23. WAC's charge is available online at http://www.libraries.rutgers.edu/rul/staff/staff.html. [Accessed 18 October 2005].

24. Protocol for adding a new scholarly resource to the Rutgers University Libraries' Web site is titled "Making Additions to our Web Pages" and is available at http://www.libraries.rutgers. edu/rul/staff/staff.html. [Accessed 18 October 2005].

25. LinkSource is the link resolver product used by the Rutgers University Libraries. For information, see http://www.ebsco.com/atoz/LinkSource.asp. [Accessed 18 October 2005].

26. The description page for Google Scholar is found by clicking on "Google Scholar" from the alphabetical list of indexes and databases available at http://www.libraries.rutgers.edu/rul/ indexes/indexes.shtml. [Accessed 18 October 2005]. The actual description page for Google Scholar is available at $\mathrm{http} / / \mathrm{www}$.libraries.rutgers.edu.proxy.libraries.rutgers.edu/rul/indexes/ search_guides/google_scholar.shtml. [Accessed 18 October 2005].

27. The ARL libraries' Web sites were accessed from the ARL homepage at http://www.arl. org/members.html. [Accessed 18 October 2005]. From the site: "ARL is a not-for-profit membership organization comprising the libraries of North American research institutions and operates as a forum for the exchange of ideas and as an agent for collective action. Membership in ARL is institutional. There are currently 123 members." This study removed the nonuniversity members to create the sample.

28. All three new items exhibited the same pattern of results; individually, news and instruction were significantly different.

29. Another academic library's experience with decision making and integrating Google Scholar into collections and services at UCLA is described in E. Meltzer, "UC Libraries Use of Google Scholar," (Aug. 15, 2005): 1-12. Available online at http://www.cdlib.org/inside/assess/evaluation_activities/docs/2005/googleScholar_summary)0805.pdf. [Accessed 18 October 2005].

30. Jasek, "How to Design Library Web Sites to Maximize Usability," 10. Jasek credits this idea to G. H. Crowley, R. Leffel, D. Ramirez, J. L. Hart, and T. S. Armstrong II, "User Perceptions of the Library's Web Pages: A Focus Group Study at Texas A\&M University," Journal of Academic Librarianship 28, no.4 (2002): 205-10.

31. A. Paula Wilson, Library Web Sites: Creating Online Collections and Services (Chicago: ALA, 2004), 77.

32. Moyo, "Collections on the Web," 51.

33. Cockrell and Jayne, "How Do I Find an Article?" 122.

34. Deborah Fallows, Search Engine Users (Washington, D.C.: Pew/Internet \& American Life Project, Jan.23, 2005), i-v, 1-29. Available online at http://www.pewinternet.org/pdfs/PIP_Searchengine_users.pdf. [Accessed 10 July 2005].

35. Cockrell and Jayne, "How Do I Find an Article?" 129. 
36. Judy Luther, “User Centered Design = Successful Products," Charleston Advisor 5, no. 3 (Jan. 2004). Available online at http://www.charlestonco.com/features.cfm?id=143\&type=np. [Accessed 18 October 2005].

37. Cockrell and Jayne, "How Do I Find an Article?" 122.

38. Ibid., 127.

39. S. Harnad, "Open Access to Peer-Reviewed Research through Author/Institution Selfarchiving: Maximizing Research Impact by Maximizing Online Access," Journal of Postgraduate Medicine 49, no.4 (2003): 337-42. Available online at http://www.jpgmonline.com/article. asp? issn=0022-3859; year=2003; volume=49;issue=4; spage=337; ;epage=342; aulast=Harnad. [Accessed 17 June 2005].

40. Burnett and Seuring, “Organising Access to Free Internet Resources," 15-16.

41. Hungyune Chao, "Assessing the Quality of Academic Libraries on the Web: The Development and Testing of Criteria," Library E Information Science Research 24 (2002): 169-94.

42. Quint, "Library Collections Linked on Google Scholar for Free." 17-18.

43. Norman Oder, "Google Scholar Links with Libraries" Library Journal (Apr. 15, 2005):

44. Jeffrey R. Young, "More Than 100 Colleges Work with Google to Speed Campus Users to Library Resources," Chronicle of Higher Education (May 11, 2005). Available online at http://chronicle. com/free/2005/05/2005051101t.htm. [Accessed 7 July 2005].

45. Google Scholar "Free Search Box Terms of Use," section 1.5. Available online at http:// scholar.google.com/scholar/scholarsearch_terms.html. [Accessed 24 July 2005]. This issue was brought forward by an entry in the blog, Digital Librarian, available at http://digitallibrarian. org/? $\mathrm{p}=88$. [Accessed 24 July 2005].

46. Marthyn Borghus, Guest Editor, "What Counts and What Doesn't: An Insider's Guide to Usage Reports," Library Connect (2005): 1-15. Available online at http://www.elsevier.com/framework_librarians/LibraryConnect/lcpamphlet7.pdf. [Accessed 12 October 2005].

47. Urban Libraries Council, “Google Scholar Survey Results 2005,” (July 2005). Available online at http://www.urbanlibraries.org/july2005-googlescholar.html. [Accessed 20 October 2005].

48. Research Libraries Group, "Mad About Metasearching," RLG TopShelf (Mar. 2005). Available online at http://www.rlg.org/en/page.php?Page_ID=7721. [Accessed 18 October 2005]; Roy Tennant, "Is Metasearching Dead?" Library Journal (July 15, 2005). Available online at http://www. libraryjournal.com/article/CA622685.html. [Accessed 30 October 2005].

49. Jerry D. Campbell, "The Case for Creating a Scholars Portal to the Web: A White Paper," portal: Libraries and the Academy 1, no.1 (2001): 15-21; Leah Graham and Panagiotis Takis Metaxas, "Of Course It's True; I Saw It on the Internet," Communications of the ACM 46, no. 5 (May 2003): 71-75; ARL Scholar's Portal. Available online at http://www.arl.org/access/scholarsportal/. [Accessed 20 October 2005]. From the site: "The Scholars Portal Project was launched in May 2002 as a multiyear collaboration between seven ARL member libraries and Fretwell-Downing. The project seeks to provide software tools for an academic community to have a single point of access on the Web to find high-quality information resources and, to the greatest extent possible, to deliver the information and related services directly to the user's desktop." Information on the Ontario Scholars Portal may be found at http://scholarsportal.info/cgi-bin/sciserv.pl?collection=journals. [Accessed 30 October 2005]. From the site: "The Ontario Scholars Portal is an initiative of the Ontario Council of University Libraries, a consortium of academic libraries across the province of Ontario, to give researchers a single point of electronic access to high-quality published journals from a broad range of disciplines. This site contains $8.5 \mathrm{M}$ articles from close to 7,000 full-text journals published by Academic Press, American Psychological Association, American Chemical Society, Berkeley Electronic Press, Cambridge University Press, Elsevier Science (Elsevier Science, Harcourt Health Sciences), Kluwer (Kluwer Academic Publishers, Kluwer Law International and Kluwer/Plenum), Oxford University Press, Project MUSE, Springer-Verlag, and John Wiley \& Sons."

50. Information about Elsevier's Scirus, a science-specific free search engine, is available online at http://www.scirus.com/srsapp/. [Accessed 5 July 2005].

51. Jeffrey R. Young, "Libraries Try to Widen Google's Eyes," Chronicle of Higher Education 50, no.37 (May 21, 2004): A1.

52. "Google Scholar Good News for Open Access," (Nov. 19, 2004). Available online at http:// www.biomedcentral.com/info/about/pr-releases?pr=20041119. [Accessed 20 October 2005].

53. Doug Payne, "Google Scholar Welcomed," Scientist (Nov. 23, 2004). Available online at http://www.biomedcentral.com/news/20041123/01. [Accessed 27 February 2005].

54. Carol Tenopir, "Google in the Academic Library," Library Journal (Feb. 1, 2005): 32.

55. "Google: Friend or Foe," Inside Higher Ed (April 11, 2005). Available online at http://www. insidehighered.com/news/2005/04/11/google. [Accessed 26 May 2005].

56. Stephen Abram, “The Google Opportunity,” Library Journal (Feb. 1, 2005): 34. 